Revista de Economia Política, vol. 30, $n^{\circ} 2$ (118), pp. 219-232, abril-junho/2010

\title{
Desindustrialização: conceituação, causas, efeitos e o caso brasileiro*
}

JOSÉ LUIS OREIRO***
CARMEM A. FEIJÓ***

\begin{abstract}
De-Industrialization: concept, causes, effects and the Brazilian case. This article aims to do a theoretical discussion about the term "de-industrialization" and its relationship with other concepts as "primarization" of exports and "Dutch disease". After that we will analyze the possible causes and effects of "de-industrialization". Finally, we analyze the Brazilian case, with a special attention over the economic literature about this issue.
\end{abstract}

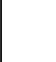

Keywords: structural change; industry; real exchange rate.

JEL Classification: L6; O14; O54.

\section{INTRODUÇÃO}

Nos últimos anos tem-se observado uma preocupação crescente entre os economistas e o público em geral a respeito de um possível processo de desindustrialização da economia brasileira. Nesse contexto, podemos observar duas posições claramente definidas. De um lado, temos os assim chamados "novo-desenvolvimentistas" que defendem a tese de que a economia brasileira vem passando por um processo de desindustrialização nos últimos 20 anos, causado pela combinação

\footnotetext{
" Os autores agradecem a contribuição de Julio Sérgio Gomes de Almeida (Unicamp/IEDI) para a elaboração deste artigo.

"Professor Adjunto do Departamento de Economia da Universidade de Brasília (UnB), Pesquisador Nível I do CNPq e Diretor da Associação Keynesiana Brasileira. E-mail: joreiro@unb.br. Página pessoal: www.joseluisoreiro.ecn.br.

**** Professora Associada do Departamento de Economia da Universidade Federal Fluminense, Pesquisadora Nível I do CNPq e Secretária Executiva da Associação Nacional dos Centros de Pós-Graduação em Economia (2008-2010). E-mail: cfeijo@terra.com.br.
} 
perversa entre abertura financeira, valorização dos termos de troca e câmbio apreciado (Loures, Oreiro e Passos, 2006; Bresser-Pereira e Marconi, 2009) ${ }^{1}$. Do outro lado, temos os assim chamados "economistas ortodoxos" que afirmam que as transformações pelas quais a economia brasileira passou nas últimas décadas não tiveram um efeito negativo sobre a indústria e que a apreciação do câmbio real resultante dessas reformas favoreceu a indústria ao permitir a importação de máquinas e equipamentos tecnologicamente mais avançados, o que permitiu a modernização do parque industrial brasileiro e, consequentemente, a expansão da própria produção industrial (Schwartsman, 2009).

Isso posto, esse pequeno artigo tem por objetivo aprofundar o debate sobre a questão da desindustrialização (ou não) da economia brasileira. Inicialmente, iremos definir de forma precisa o termo "desindustrialização" para isolar o debate em consideração de temas conexos como, por exemplo, "re-primarização da pauta de exportações" e "doença holandesa". Na sequência iremos nos debruçar sobre as possíveis causas do processo de desindustrialização e as suas possíveis consequências sobre o crescimento de longo prazo de uma economia capitalista. Iremos finalizar essa nota com algumas evidências empíricas a respeito da ocorrência da desindustrialização na economia brasileira.

\section{SOBRE O CONCEITO DE DESINDUSTRIALIZAÇÃO}

O conceito "clássico" de "desindustrialização" foi definido por Rowthorn e Ramaswany (1999) como sendo uma redução persistente da participação do emprego industrial no emprego total de um país ou região. Com base nesse conceito, os assim chamados países desenvolvidos ou do "primeiro mundo" teriam passado por um forte processo de desindustrialização a partir da década de 1970; ao passo que a América Latina teria passado pelo mesmo processo na década de 1990, o que coincide com o período de implantação das políticas liberalizantes associadas ao “consenso de Washington" (ver Tabela I).

\footnotetext{
${ }^{1}$ Sobre o "novo-desenvolvimentismo" e as suas diferenças com o "velho-desenvolvimentismo", ver Bresser-Pereira (2006), Sicsú, Paula e Michel (2007), Oreiro e Paula (2009) e Bresser-Pereira e Gala (2010).
} 
Tabela I: Participação da Indústria no Emprego (\% do total)

\begin{tabular}{|l|r|r|r|r|r|}
\hline Região: & 1960 & 1970 & 1980 & 1990 & 1998 \\
\hline África Subsaariana & 4.4 & 4.8 & 6.2 & 5.5 & 5.5 \\
\hline América Latina e Caribe & 15.4 & 16.3 & 16.5 & 16.8 & 14.2 \\
\hline \multicolumn{1}{|c|}{ Cone Sul e Brasil } & 17.4 & 17.2 & 16.2 & 16.6 & 11.8 \\
\hline Ásia Ocidental e Norte da África & 7.9 & 10.7 & 12.9 & 15.1 & 15.3 \\
\hline Sul da Ásia & 8.7 & 9.2 & 10.7 & 13.0 & 13.9 \\
\hline Leste da Ásia (exceto China e Japão) 10.0 & 10.0 & 10.4 & 15.8 & 16.6 & 14.9 \\
\hline \multicolumn{1}{|c|}{ NIEs } & 10.5 & 12.9 & 18.5 & 21.0 & 16.1 \\
\hline China & 10.9 & 11.5 & 10.3 & 13.5 & 12.3 \\
\hline Terceiro mundo & 10.2 & 10.8 & 11.5 & 13.6 & 12.5 \\
\hline Primeiro mundo & 26.5 & 26.8 & 24.1 & 20.1 & 17.3 \\
\hline
\end{tabular}

Fonte: Palma (2005, p. 5)².

Mais recentemente, Tregenna (2009) redefiniu de forma mais ampla o conceito "clássico" de desindustrialização como sendo uma situação na qual tanto o emprego industrial como o valor adicionado da indústria se reduzem como proporção do emprego total e do PIB, respectivamente.

A primeira observação importante a respeito do conceito ampliado de "desindustrialização" é que o mesmo é compatível com um crescimento (expressivo) da produção da indústria em termos físicos. Em outras palavras, uma economia não se desindustrializa quando a produção industrial está estagnada ou em queda, mas quando o setor industrial perde importância como fonte geradora de empregos e/ ou de valor adicionado para uma determinada economia. Dessa forma, a simples expansão da produção industrial (em termos de quantum) não pode ser utilizada como "prova" da inexistência de desindustrialização.

\footnotetext{
${ }^{2}$ Economias incluídas sob o título "Terceiro Mundo": África Subsaariana: Benin, Botsuana, Burkina Faso, Camarões, República Central Africana, Chade, República Democrática do Congo, Costa do Marfim, Gabão, Gana, Quênia, Lesotho, Malawi, Mali, Mauritânia, Maurício, Nigéria, República do Congo, Ruanda, Senegal, África do Sul, Togo, Zâmbia e Zimbábue.

América Latina e Caribe: Argentina, Brasil, Chile, Colômbia, Costa Rica, República Dominicana, Equador, El Salvador, Guatemala, Honduras, Jamaica, México, Nicarágua, Panamá, Paraguai, Peru e Uruguai (dentro dessa categoria, a subcategoria "Cone Sul” inclui Argentina, Chile e Uruguai).

Ásia Ocidental e Norte da África: Argélia, Egito, Marrocos, Oman, Arábia Saudita, Tunísia e Turquia.

Sul da Ásia: Bangladesh, Índia, Paquistão e Sri Lanka.

Leste Asiático: Hong Kong SAR, Indonésia, Malásia, Filipinas, República da Coreia, Cingapura, Tailândia e Taiwan Província da China (dentro dessa categoria, a subcategoria NIEs 1 inclui: Hong Kong SAR, República da Coreia, Cingapura e Taiwan (Província da China).

Economias incluídas sob o título "Primeiro Mundo": Austrália, Áustria, Bélgica, Canadá, Dinamarca, Finlândia, França, Grécia, Itália, Japão, Luxemburgo, Holanda, Nova Zelândia, Noruega, Portugal, Espanha, Suécia, Reino Unido e Estados Unidos.
} 
A segunda observação é que a desindustrialização não está necessariamente associada a uma "re-primarização da pauta de exportação". Com efeito, a participação da indústria no emprego e no valor adicionado pode se reduzir em função da transferência para o exterior das atividades manufatureiras mais intensivas em trabalho e/ou com menor valor adicionado. Se assim for, a desindustrialização pode vir acompanhada por um aumento da participação de produtos com maior conteúdo tecnológico e maior valor adicionado na pauta de exportações. Nesse caso, a desindustrialização é classificada como "positiva". No entanto, se a desindustrialização vier acompanhada de uma "re-primarização" da pauta de exportações, ou seja, por um processo de reversão da pauta exportadora na direção de commodities, produtos primários ou manufaturas com baixo valor adicionado e/ou baixo conteúdo tecnológico; então isso pode ser sintoma da ocorrência de "doença holandesa", ou seja, a desindustrialização causada pela apreciação da taxa real de câmbio resultante da descoberta de recursos naturais escassos num determinado país ou região. Nesse caso, a desindustrialização é classificada como "negativa", pois é o resultado de uma "falha de mercado" na qual a existência e/ ou a descoberta de recursos naturais escassos, para os quais o preço de mercado é superior ao custo marginal social de produção, gera uma apreciação da taxa de

câmbio real, produzindo assim uma externalidade negativa sobre o setor produtor de bens manufaturados (Bresser-Pereira, 2008).

\section{SOBRE AS CAUSAS DA DESINDUSTRIALIZAÇÃO}

Segundo Rowthorn e Ramaswany (1999), a desindustrialização pode ser causada por fatores internos e externos a uma determinada economia. Os fatores internos seriam basicamente dois, a saber: uma mudança na relação entre a elasticidade renda da demanda por produtos manufaturados e serviços e o crescimento mais rápido da produtividade na indústria do que no setor de serviços.

Nesse contexto, o processo de desenvolvimento econômico levaria "naturalmente" todas as economias a se desindustrializar a partir de um certo nível de renda per capita. Isso porque a elasticidade renda da demanda de serviços tende a crescer com o desenvolvimento econômico, tornando-se maior do que a elasticidade renda da demanda por manufaturados. Dessa forma, a continuidade do desenvolvimento econômico levará a um aumento da participação dos serviços no PIB e, a partir de um certo nível de renda per capita, a uma queda da participação da indústria no PIB. Além disso, como a produtividade do trabalho cresce mais rapidamente na indústria do que nos serviços, a participação do emprego industrial deverá iniciar seu processo de declínio antes da queda da participação da indústria no valor adicionado.

Os fatores externos que induzem a desindustrialização estão relacionados ao grau de integração comercial e produtiva das economias, ou seja, com o estágio 
alcançado pelo assim clamado processo de "globalização". Nesse contexto, os diferentes países podem se especializar na produção de manufaturados (o caso da China e da Alemanha) ou na produção de serviços (Estados Unidos e Reino Unido). Além disso, alguns países podem se especializar na produção de manufaturados intensivos em trabalho qualificado, ao passo que outros podem se especializar na produção de manufaturados intensivos em trabalho não qualificado. Esse padrão de desenvolvimento gera uma redução do emprego industrial (em termos relativos) no primeiro grupo e um aumento do emprego industrial no segundo grupo.

Por fim, a relação entre a participação do emprego (e do valor adicionado) da indústria e a renda per capita pode ser afetada pela "doença holandesa" (Palma, 2005). Nesse contexto, a abundância de recursos naturais pode induzir a uma redução da participação da indústria no emprego e no valor adicionado por intermédio da apreciação cambial, a qual resulta em perda de competitividade da indústria e déficit comercial crescente da mesma. Em outras palavras, a desindustrialização causada pela "doença holandesa" está associada a déficits comerciais crescentes da indústria e superávits comerciais (crescentes) no setor não industrial.

A desindustrialização causada pela "doença holandesa” é também denominada de "desindustrialização precoce"; uma vez que a mesma se iniciaria a um nível de renda per capita inferior ao observado nos países desenvolvidos quando os mesmos iniciaram o seu processo de desindustrialização. Sendo assim, os países afetados pela "doença holandesa" iniciam o seu processo de desindustrialização sem terem alcançado o "ponto de maturidade" de suas respectivas estruturas industriais e, portanto, sem ter esgotado todas as possibilidades de desenvolvimento econômico que são permitidas pelo processo de industrialização.

\section{CONSEQUÊNCIAS DA DESINDUSTRIALIZAÇÃO}

No contexto dos modelos neoclássicos de crescimento a ocorrência ou não do fenômeno da desindustrialização é irrelevante, haja vista o crescimento de longoprazo é consequência apenas da "acumulação de fatores" e do "progresso tecnológico", sendo independente da composição setorial da produção. Para esses modelos, uma unidade de valor adicionado tem o mesmo significado para o crescimento de longo prazo seja ela gerada na indústria, na agricultura e no setor de serviços.

As diversas correntes do pensamento heterodoxo, contudo, consideram que o processo de crescimento econômico é setor-específico. Mais precisamente, os economistas heterodoxos acreditam que a indústria é o motor do crescimento de longo prazo das economias capitalistas (Thirwall, 2002; Tregenna, 2009), uma vez que:

(i) Os efeitos de encadeamento para a frente e para trás na cadeia produtiva são mais fortes na indústria do que nos demais setores da economia.

(ii) A indústria é caracterizada pela presença de economias estáticas e dinâmi- 
cas de escala, de tal forma que a produtividade na indústria é uma função crescente da produção industrial. Esse fenômeno é conhecido na literatura econômica como "lei de Kaldor-Verdoorn" 3

(iii) A maior parte da mudança tecnológica ocorre na indústria. Além disso, boa parte do progresso tecnológico que ocorre no resto da economia é difundido a partir do setor manufatureiro.

(iv) A elasticidade renda das importações de manufaturas é maior do que a elasticidade renda das importações de commodities e produtos primários. Dessa forma, a "industrialização" é tida como necessária para aliviar a restrição de balanço de pagamentos ao crescimento de longo prazo 4 .

Em suma, a indústria é vista como "especial" pelo pensamento heterodoxo, pois ela é a fonte de retornos crescentes de escala (indispensável para a sustentação do crescimento no longo-prazo), é a fonte e/ou a principal difusora do progresso tecnológico e permite o relaxamento da restrição externa ao crescimento de longoprazo.

Nesse contexto, a desindustrialização é um fenômeno que tem impacto negativo sobre o potencial de crescimento de longo-prazo, pois reduz a geração de retornos crescentes, diminui o ritmo de progresso técnico e aumenta a restrição externa ao crescimento.

\section{O CASO BRASILEIRO}

Um dos primeiros estudos a apontar para a desindustrialização da economia brasileira foi Marquetti (2002). Segundo dados apresentados por esse autor para a indústria de transformação (ver Tabela II), a economia brasileira teria passado por um processo de desindustrialização nas décadas de 1980 e 1990 tanto em termos da participação do emprego como da participação no valor adicionado. Segundo Marquetti, a "desindustrialização" ocorrida nesse período teria sido consequência do baixo investimento realizado na economia brasileira, particularmente na indústria. Ainda segundo esse autor, o processo de desindustrialização ocorrido nesse período seria essencialmente negativo sobre os prospectos de crescimento da economia brasileira, haja vista que estaria associado à transferência de recursos e de trabalho da indústria para setores com menor produtividade do trabalho, gerando assim um menor crescimento do produto potencial no longo prazo.

\footnotetext{
${ }^{3}$ Evidência empíricas a respeito da "lei de Kaldor-Verdoorn" podem ser obtidas em McCombie e De Ridder (1984).

${ }^{4}$ Sobre a restrição de balanço de pagamentos ao crescimento de longo prazo e o papel desempenhado pela estrutura produtiva na determinação das elasticidades renda das importações e das exportações, ver McCombie e Roberts (2002).
} 
Tabela II: Participação Relativa da Indústria de Transformação no

Valor Adicionado (VA) e no Pessoal Ocupado (PO) em \% (1980-1998).

\begin{tabular}{lllllllllllll}
\hline & 1980 & 1985 & 1988 & 1990 & 1991 & 1992 & 1993 & 1994 & 1995 & 1996 & 1997 & 1998 \\
\hline VA & 31,3 & 31,6 & 28,6 & 25,7 & 23,8 & 22,7 & 21,6 & 21 & 20,6 & 20 & 18,2 & 19,1 \\
PO & 15,5 & 14,6 & 13,9 & 13,9 & 13,8 & 13,5 & 13,4 & 12,9 & 12,4 & & & \\
\hline
\end{tabular}

Fonte: Marquetti (2002, p. 121).

Um outro estudo que aponta a ocorrência inequívoca de desindustrialização no Brasil nas décadas de 1980 e 1990 é Bonelli (2005). Com base nas informações fornecidas pelas contas nacionais do Brasil, a participação da indústria no PIB a custo de fatores teria se reduzido de 42,3\% em 1985 para apenas 31,4\% em 1995, ou seja, uma queda de cerca de 11 p.p. com respeito ao PIB em apenas dez anos (Ibid., p. 10). Essa queda foi basicamente o resultado da redução da participação da indústria de transformação, cuja participação no PIB a custos de fatores se reduziu de 31,62\% em 1985 para 20,60\% em 1995. Esse processo de "perda do peso relativo da indústria no PIB" foi causado pelas mudanças pelas quais passou a economia brasileira no final da década de 1980 e início da década de 1990, a saber: aumento da competição interna e externa, causado pela abertura comercial e financeira, privatização em diversos segmentos industriais, e sobre-valorização da taxa real de câmbio no período 1995-1998 (Ibid., pp. 22-23).

Feijó, Carvalho e Almeida (2005) também apresentam evidências contundentes de desindustrialização na economia brasileira durante as décadas de 1980 e 1990. Segundo esses autores "o peso da indústria de transformação cai de 32,1\% do PIB em 1986 para 19,7\% do PIB em 1998, queda de 12 pontos percentuais, muito alta sob qualquer critério de avaliação" (p. 1). O estudo em consideração, no entanto, questiona o caráter negativo dessa desindustrialização, uma vez que os "resultados mostram que a indústria brasileira preserva representatividade de todos os segmentos básicos segundo a classificação tecnológica” (p. 20).

$\mathrm{Na}$ mesma linha dos trabalhos anteriores, Almeida (2006) mostra que a participação da indústria de transformação no PIB apresentou uma nítida tendência a queda no período compreendido entre 1985 e 1998 (Figura 1). Essa tendência teria sido, no entanto, parcialmente revertida a partir de 1999, com a mudança do regime cambial brasileiro, o que possibilitou, pelo menos até 2005, a redução ou eliminação da sobrevalorização cambial ocorrida no período 19951998. 
Figura 1: Brasil - Participação da Indústria de Transformação no PIB - \%

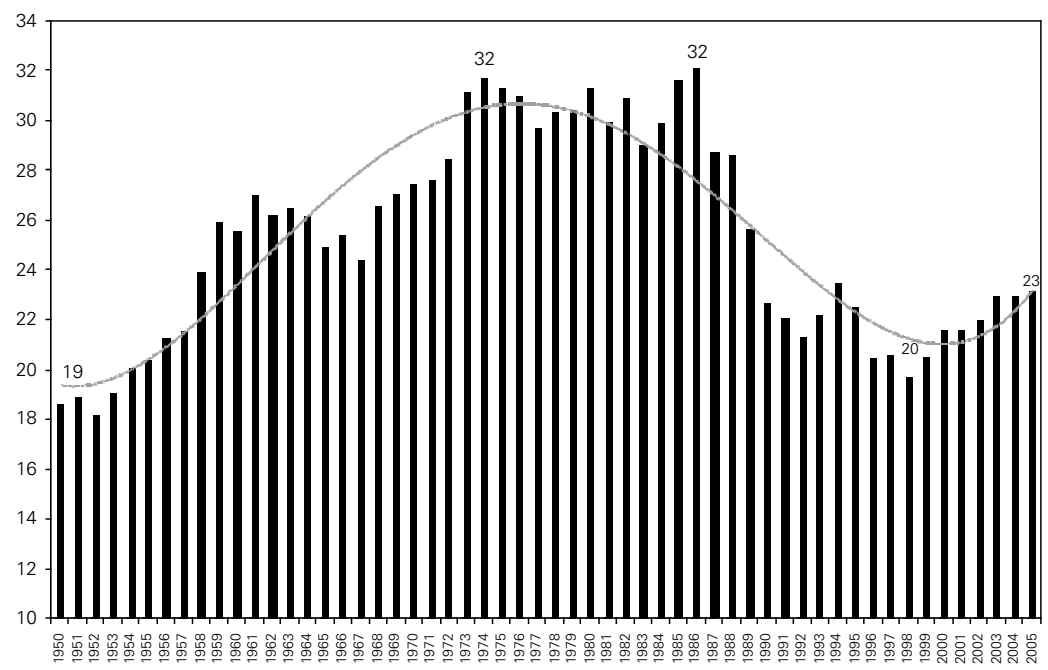

Indústria de Transformação / PIB - \%

Tendência

Fonte: Almeida (2006).

Argumentos contrários à tese de desindustrialização foram apresentados por Nassif (2008). Segundo esse autor, "Não se pode falar que o Brasil tenha passado por um processo de desindustrialização porque não se assistiu a um processo generalizado de mudança na realocação de recursos produtivos e no padrão de especialização dos setores com tecnologias intensivas em escala, diferenciada e science-based para as indústrias baseadas em recursos naturais e em trabalho" (p. 89). A sua afirmação está apoiada numa análise pormenorizada da composição do valor adicionado na indústria brasileira, por tipo de tecnologia, para o período 1996-2004.

De acordo com os dados apresentados por Nassif, a participação no valor adicionado da indústria dos setores intensivos em recursos naturais e em trabalho teria passado de 46,26\% em 1996 para 49,79\% em 2004; ao passo que a participação conjunta dos setores intensivo em escala, diferenciada e baseado em ciência passou de 53,72\% em 1996 para 50,15\% em 2004. Dessa forma, se observa uma relativa estabilidade da estrutura industrial brasileira no período em consideração, o que descartaria, portanto, a ocorrência de um processo de desindustrialização. Deve-se ressaltar, contudo, que o autor em consideração parece confundir os conceitos de desindustrialização e “doença holandesa”. Com efeito, para Nassif, a desindustrialização não seria um processo de perda de importância da indústria (no emprego e no valor adicionado), mas de mudança na estrutura interna da própria indústria em direção a setores intensivos em recursos naturais e trabalho ${ }^{5}$. Definido

\footnotetext{
${ }^{5}$ Nassif reconhece, no entanto, a ocorrência de uma redução significativa da participação da indústria de transformação no PIB brasileiro a partir da segunda metade da década de 1980. Nas suas palavras:
} 
dessa forma, o conceito de "desindustrialização" torna-se indistinguível do conceito de "doença holandesa". Contudo, a literatura sobre desindustrialização deixa claro que a mesma pode ocorrer mesmo na ausência de doença holandesa.

Com base na literatura brasileira sobre o tema parece impossível negar que a economia brasileira tenha passado por um processo de desindustrialização no período 1986-1998. De fato, os estudos de Marquetti (2002), Bonelli (2005), Feijó et al (2005), Almeida (2006) e, até mesmo, Nassif (2008) apontam nessa direção. Contudo, a controvérsia recente sobre o tema, principalmente o debate travado nos jornais de grande circulação diária e em outros veículos de comunicação, parece se limitar ao comportamento da indústria brasileira no período posterior a mudança do regime cambial, notadamente o período 2004-2008, no qual se verificou uma aceleração da taxa de crescimento do valor adicionado da indústria de transformação relativamente ao período 1995-19996. Os economistas ortodoxos insistem na tese de que, para esse período, não existem dados que comprovem a continuidade do processo de desindustrialização da economia brasileiro. Pelo contrário, as mudanças macroeconômicas pelas quais o Brasil passou pós-1999, com a implementação do tripé metas de inflação-superávit primário-câmbio flutuante, teria permitido um crescimento bastante robusto da produção industrial, eliminando assim o fantasma da desindustrialização.

A grande dificuldade para se avaliar a continuidade ou não do processo de desindustrialização no período posterior à mudança do regime cambial brasileiro se encontra na mudança da metodologia de cálculo do PIB implementada pelo IBGE no primeiro trimestre de 2007. Conforme se explica pormenorizadamente na nota técnica $01 \mathrm{em}$ anexo, a mudança metodológica implementada pelo IBGE inviabiliza a comparação entre as séries da participação do valor adicionado na indústria no PIB nos períodos anterior e posterior a 1995. Essa dificuldade técnica tem permitido que alguns economistas ortodoxos simplesmente neguem a ocorrência de desindustrialização na economia brasileira, alegando a ausência de dados que permitam inferir a ocorrência da mesma ${ }^{7}$. Soma-se a isso o fato de que a par-

\footnotetext{
"Na segunda metade dos anos 1980, no entanto, observa-se uma significativa mudança na evolução da estrutura produtiva brasileira. Com efeito, após preservar, de forma relativamente estável, uma participação média anual de 30,7\% no PIB entre 1973 e 1985 e de alcançar participação recorde de 32\% no PIB em 1986, a indústria de transformação começa a perder, de forma sustentada, significativa participação relativa no fluxo global de riqueza do país. No início do processo de liberalização comercial, em 1990, essa participação já havia sido reduzida para 22,7\%" (2008, p. 83).

${ }^{6}$ Nas palavras de Schwartsman (2009): “Não é a primeira vez que ouvimos esta conversinha [...] O
curioso é ouvi-la de novo, logo após a previsão ter se mostrado completamente errada pelo desenvolvi-
mento do país nos últimos anos até a eclosão da crise (grifo nosso). De fato, o crescimento, não só da
produção industrial, mas do PIB, acelerou-se consideravelmente até setembro de 2008 . No que se
refere à primeira, a taxa média de expansão em quatro anos atingiu algo como $4,5 \%$ ao ano (grifo
nosso), quase três vezes superior à registrada em períodos anteriores. Além disto, como já destacado
aqui, o crescimento foi liderado pelos setores de maior intensidade exportadora, fenômeno difícil de
conciliar com a afirmação acerca da influência negativa do câmbio sobre a atividade industrial”.
${ }^{7}$ Conforme foi visto à exaustão nos parágrafos anteriores, a literatura brasileira sobre o tema, apoian-
} 
ticipação da indústria de transformação no PIB a preços correntes no período 1999-2004 ter apresentado uma notável recuperação (ver Figura 3), ensejando assim alguns economistas ortodoxos a mencionar a ocorrência de uma possível "re-industrialização" da economia brasileira.

Nesse contexto, para analisar a perda de importância relativa da indústria, notadamente a indústria de transformação, no PIB, a comparação ao longo das décadas de 1990 e 2000 deve lançar mão de evidências indiretas que contornem a dificuldade de se comparar diretamente a evolução da participação percentual do valor adicionado a preços correntes dos setores no total da economia.

Conforme se observa na Figura 2, onde são apresentadas as taxas de crescimento da indústria e do PIB, bem como a taxa real efetiva de câmbio, no período 1996-2008, apenas em três anos a taxa de crescimento da indústria superou a da economia, a saber: 2000, 2003 e 2004. Nos demais anos, o PIB cresceu à frente do valor adicionado da indústria de transformação, revelando assim continuidade da perda de dinamismo da indústria no período posterior a 1995. Verificamos também que a forte apreciação da taxa real efetiva de câmbio no período 2004-2008 foi acompanhada pela perda de dinamismo da indústria de transformação com respeito ao resto da economia brasileira. De fato, entre 2005 e 2008 a taxa de crescimento do valor adicionado da indústria de transformação ficou sistematicamente abaixo da taxa de crescimento do PIB. Esse movimento foi acompanhado por uma forte apreciação do câmbio real.

Figura 2: Taxa de crescimento do PIB e da Indústria de Transformação (\%)

e Taxa Real Efetiva de Câmbio (1996-2008)

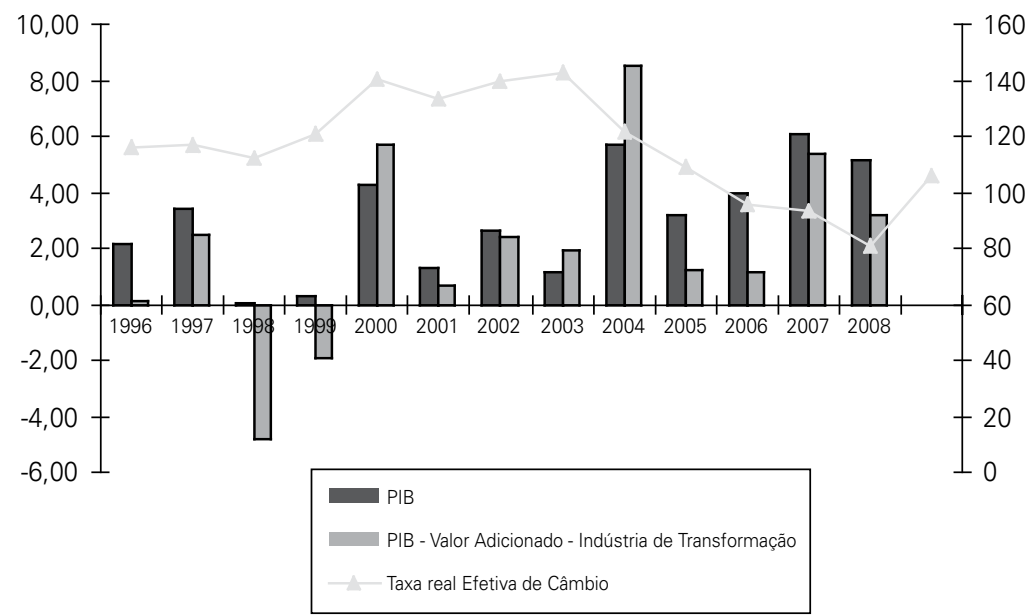

Fonte: IBGE, Contas Nacionais Trimestrais; IPEADATA.

do-se nos dados das contas nacionais anteriores à mudança metodológica do IBGE no primeiro trimestre de 2007, aponta claramente para a ocorrência de desindustrialização no período 1986-1998. 
A Figura 3 permite qualificar melhor o sentido da perda de importância da indústria na medida em que compara o valor adicionado da indústria de transformação com o PIB a preços de 1995, ou seja, isola o efeito da variação dos preços na evolução da participação da indústria no total. O ponto de destaque é que sem o efeito da variação dos preços, a queda na participação da indústria de transformação no PIB é mais nítida. A maior participação registrada na série a preços constantes foi em 1996 (18,3\%), e mesmo o maior dinamismo relativo da indústria no biênio 2003-2004 não recuperou o peso da indústria na segunda metade dos anos 1990. Esta é uma indicação que reforça o efeito negativo da tendência à valorização do câmbio sobre o setor manufatureiro.

Figura 3: Participação do Valor Adicionado da Indústria de Transformação a preços de 1995 (1996 a 2008)

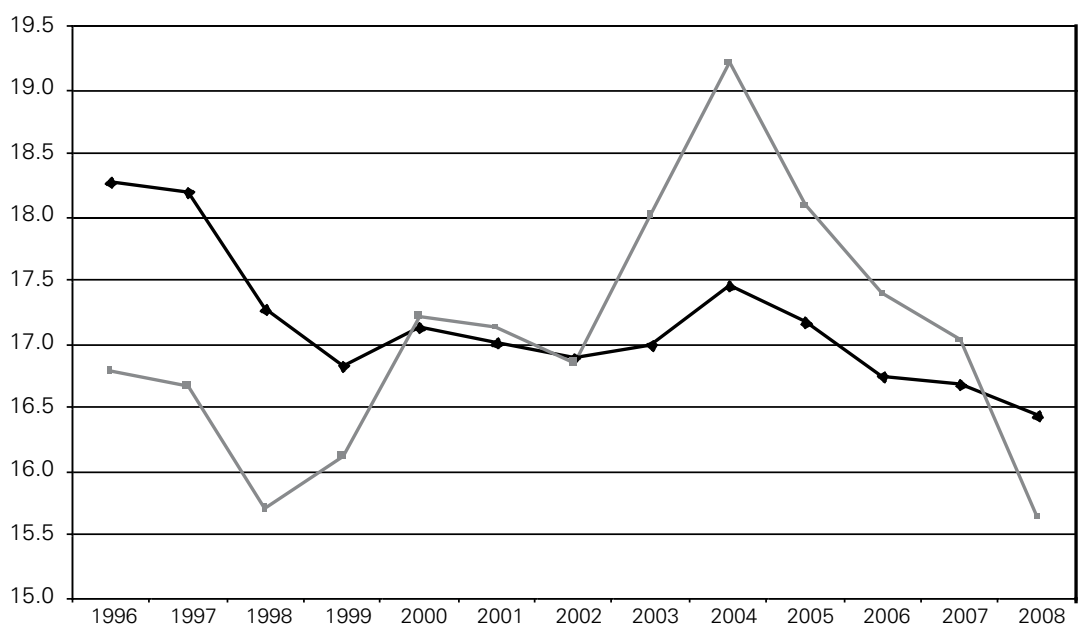

— Participação a preços de $1995 \quad$ — Participação a preços correntes

Fonte: IBGE, Contas Nacionais Trimestrais

A partir do que foi exposto nos parágrafos anteriores, parece haver pouca margem para a dúvida a respeito da ocorrência de um processo de desindustrialização da economia brasileira, mesmo após a mudança do regime cambial em 1999. Nesse contexto, o ponto que ainda pode ser objeto de divergência refere-se às causas desse processo. Mais precisamente, trata-se de debater se esse fenômeno é um resultado natural do estágio de desenvolvimento da economia brasileira ou se é a consequência das políticas macroeconômicas adotadas nos últimos 20 anos. Um ponto particularmente importante é avaliar se o processo de desindustrialização da economia brasileira resulta da ocorrência de "doença holandesa".

No que se refere à relação entre desindustrialização e "doença holandesa", um estudo recente divulgado pelo IEDI (Valor Econômico, 22/12/2009) mostra que no 
período 2004-2009 o saldo comercial da indústria (acumulado de janeiro a setembro) passou de 17,09 bilhões de dólares em 2004 para -4,83 bilhões de dólares em 2009. Ao desagregar esse saldo por intensidade tecnológica verificamos que os setores de média-alta e alta intensidade tecnológica não são apenas deficitários, como ainda presenciaram um crescimento expressivo do déficit comercial no período em consideração. Com efeito, o déficit do setor de média-alta intensidade passou de 2,07 bilhões de dólares em 2004 para 19,19 bilhões de dólares em 2009, ao passo que o déficit do setor de alta intensidade passou de 5,58 bilhões de dólares em 2004 para 12,65 bilhões de dólares em 2009. O crescimento do déficit comercial da indústria, principalmente nos setores de maior intensidade tecnológica, no período 2004-2009 coincide com a redução da participação do valor adicionado da indústria de transformação no PIB, conforme podemos constatar na Figura 3. A ocorrência simultânea de perda da importância da indústria no PIB e aumento do déficit comercial da indústria é um sintoma claro de ocorrência de "doença holandesa", segundo a definição de Palma (2005).

Um argumento similar a esse é desenvolvido por Bresser-Pereira e Marconi (2008). Segundo esses autores, a desindustrialização da economia brasileira seria o resultado da "doença holandesa", uma vez que, no período 1992-2007, o saldo da balança comercial de commodities apresentou um superávit crescente - passando de US\$ 11 bilhões em 1992 para US\$ 46,8 bilhões em 2007 — ao passo que o saldo da balança comercial de manufaturados passou de um superávit de US\$ 4 bilhões em 1992 para um déficit de US\$ 9,8 bilhões em 2007. No caso dos manufaturados de média-alta e alta tecnologia a deterioração do saldo comercial foi ainda mais dramática: o déficit nessa categoria passou de US\$ 0,7 bilhões em 1992 para US\$20,2 bilhões em 2007. Esses dados apontam, portanto, para um aumento da participação das commodities e uma redução da participação dos manufaturados (que passaram a ter contribuição negativa) no saldo da balança comercial no período 1992-2007. Como nesse período ocorreu simultaneamente uma perda relativa de importância da indústria na economia brasileira, segue-se que a desindustrialização foi o resultado da "doença holandesa".

Mesmo se considerarmos a estrutura da indústria brasileira com base na composição do valor adicionado da mesma, tal como Nassif (2008), iremos constatar a existência de inquietantes sinais de "doença holandesa". Com efeito, os setores da indústria brasileira mais sofisticados do ponto de vista tecnológico, ou seja, os setores intensivo em escala, diferenciado e baseado em ciência, tiveram a sua participação no valor adicionado da indústria reduzida de 53,72\% em 1996 para $50,15 \%$ em 2004. Trata-se de uma queda não desprezível de mais de 3 p.p. no espaço de menos de uma década. Daqui se segue que existem sinais não desprezíveis de mudança no padrão de especialização da estrutura produtiva da economia brasileira na direção de atividades intensivas em recursos naturais e de baixo conteúdo tecnológico. 


\section{CONCLUSÃO}

O presente artigo teve por objetivo inicial fazer uma discussão teórico-conceitual a respeito do termo "desindustrialização" e a relação do mesmo com os conceitos de "re-primarização" da pauta de exportações e "doença holandesa". $\mathrm{Na}$ sequência foram analisadas as possíveis causas e consequências do processo de desindustrialização. Por fim, analisou-se o caso brasileiro, com ênfase na literatura nacional existente sobre o tema. No que se refere a esse ponto, a literatura brasileira dos últimos dez anos apresenta evidências conclusivas a respeito da ocorrência de desindustrialização na economia brasileira para o período 1986-1998. Para o período posterior à mudança do regime cambial, a continuidade do processo de desindustrialização não pode ser estabelecida de forma tão conclusiva, em função da mudança na metodologia de apuração das Contas Nacionais pelo IBGE em 2007. Contudo, os dados a respeito da taxa de crescimento da indústria de transformação apontam para a continuidade da perda de importância relativa da indústria brasileira nos últimos 15 anos. Por fim, estudos recentes a respeito da composição do saldo comercial brasileiro e da composição do valor adicionado da indústria brasileira mostram sinais inquietantes da ocorrência de "doença holandesa", ou seja, de desindustrialização causada pela apreciação da taxa real de câmbio que resulta da valorização dos preços das commodities e dos recursos naturais no mercado internacional.

\section{REFERÊNCIAS BIBLIOGRÁFICAS}

Almeida, J.S.G. (2006). "Política Monetária e Crescimento Econômico no Brasil”. Seminário do PSDB, 16 de fevereiro.

Bonelli, R. (2008). "Industrialização e Desenvolvimento: notas e conjecturas com foco na experiência do Brasil". Conferência de Industrialização, Desindustrialização e Desenvolvimento, Federação das Indústrias do Estado de São Paulo, Agosto.

Bresser-Pereira, L.C. (2006). “O Novo-Desenvolvimentismo e a Ortodoxia Convencional”. São Paulo em Perspectiva, Vol. 20, N.1.

Bresser-Pereira, L.C. - (2008). "The Dutch Disease and Its Neutralization: a Ricardian Approach", Revista de Economia Política, Vol. 28, N.1.

Bresser-Pereira, L.C; Marconi, N. (2008). "Existe doença holandesa no Brasil?”. Anais do IV Fórum de Economia de São Paulo, Fundação Getúlio Vargas: São Paulo.

Bresser-Pereira, L.C; Marconi, N. (2009). "Doença Holandesa e Desindustrialização”. Valor Econômico, 25 de novembro.

Bresser-Pereira, L.C; Gala, P. (2010). "Macroeconomia Estruturalista do Desenvolvimento e NovoDesenvolvimentismo". Revista de la Cepal, N. 100 [no prelo].

Feijó, C.A; Carvalho, P.G; Almeida, J.S.G. (2005). “Ocorreu uma desindustrialização no Brasil?”. São Paulo: IEDI, Novembro, mimeo.

IBGE, Diretoria de Pesquisa-DPE, Coordenação de Contas Nacionais- CONAC, Sistema de Contas Nacionais -Brasil Referência 2000 Nota metodológica no. 9, Anos Correntes, disponível em www.ibge.gov.br, acesso em 6 de janeiro de 2010

Marquetti, A. (2002). "Progresso Técnico, Distribuição e Crescimento na Economia Brasileira: 19551998". Estudos Econômicos, Vol. 32, N.1.

Loures, R.R; Oreiro, J.L; Passos, C.A.K. (2006). "Desindustrialização: a crônica da servidão consentida”. Economia e Tecnologia, Ano 2, Vol. 4. 
McCombie, J.S.L; De Ridder, J.R. (1984). “The Verdoorn Law Controversy: some empirical evidence using U.S. State data". Oxford Economic Papers, Vol. 36, N.2.

McCombie, J.S.L; Roberts, M. (2002). "The role of the balance of payments in economic growth" In: Setterfield, M. (ed.). The Economics of Demand-Led Growth. Edward Elgar: Aldershot.

Nassif, A. (2008). "Há Evidências de Desindustrialização no Brasil?”. Revista de Economia Política, Vol. 28, N.1.

Oreiro, J.L; Paula, L.F. (2009). "Novo-Desenvolvimentismo e a Agenda de Reformas Macroeconômicas para o Crescimento Sustentado com Estabilidade de Preços e Equidade Social”. Associação Keynesiana Brasileira, Disponível em http://www.ppge.ufrgs.br/akb/clipping.asp.

Palma, G. (2005). "Quatro fontes de desindustrialização e um novo conceito de doença holandesa". Conferência de Industrialização, Desindustrialização e Desenvolvimento, Federação das Indústrias do Estado de São Paulo, Agosto.

Rowthorn, R; Ramaswany, R (1999). “Growth, Trade and Deindustrialization”. IMF Staff Papers, Vol. 46, N.1.

Schwartsman, A. (2009). "Uma Tese com Substâncias". Folha de São Paulo, 19 de agosto.

Sicsú, J; Paula, L.F; Michel, R. (2007). "Por que novo-desenvolvimentismo?”. Revista de Economia Política, Vol. 27, n.4.

Thirwall, A. (2002). The Nature of Economic Growth. Edward Elgar: Aldershot.

Tregenna, F. (2009). "Characterizing deindustrialization: an analysis of changes in manufacturing employment and output internationally". Cambridge Journal of Economics, Vol. 33.

Valor Econômico. "Indústria pode ter déficit comercial recorde no próximo ano, diz IEDI", $22 / 12 / 2009$.

\section{NOTA TÉCNICA 01}

\section{Mudança do ano-base para 2000 das Contas Nacionais divulgada no $1^{\circ}$ Trimestre de 2007.}

Um procedimento metodológico recomendado aos órgãos produtores de estatísticas oficiais é a revisão periódica das séries históricas com vistas à incorporação de melhorias nos procedimentos de cálculo das estimativas dos agregados macroeconômicos. Seguindo as recomendações internacionais, em 2007, o IBGE divulgou a série do PIB tendo o ano 2000 como base de referência ${ }^{8}$. Conquanto revisões que melhorem a qualidade das estimativas sejam bem-vindas, elas também apresentam um ônus para o pesquisador por, na maioria das vezes, representar uma quebra na comparabilidade dos dados ao longo do tempo. Este é o caso para a economia brasileira na década de 1990, uma década marcada por grandes transformações no cenário macroeconômico nacional que afetaram profundamente sua estrutura produtiva, pois a revisão do PIB na nova base retroagiu até o ano de 1995 , não incluindo a primeira metade da década. ${ }^{9}$

Com a mudança do ano de referência para 2000, o IBGE retroagiu a série histórica do PIB trimestral até o $1^{\circ}$ trimestre de 1995 . Os agregados de 1995 a 1999 foram estimados aplicando-se índices de volume e de preços aos valores estimados para economia no ano 2000. Como as estimativas dos agregados do ano 2000 incorporaram, dentre outras coisas, pesquisas setoriais com maior representatividade de pequenos e médios estabelecimentos, a estrutura dos totais estimados dessa forma difere das estimativas obtidas antes da mudança da base de referência. Assim, ao se estimar a segunda metade dos anos 1990 com base na estrutura da economia em 2000, as séries das Contas Nacionais em valores não são compatíveis com as da primeira metade dos anos 1990 (a partir de quando o IBGE passou a divulgar as Contas Nacionais segundo o Novo Sistema), quando as estimativas basearam-se, em muitos casos, em pesquisas com amostras menos robustas.

\footnotetext{
${ }^{8}$ Segundo IBGE (Nota metodológica n. 9, p. 2): “Esta nova série caracteriza-se, principalmente, por um trabalho de atualização dos conceitos adotados, incorporação de novas fontes de dados e de resultados de pesquisas realizadas especificamente para o ano de referência, e o estabelecimento de marcos estruturais que serão referências para os anos subsequentes".

${ }^{9}$ Vale lembrar que em 1997 o IBGE lançou o Novo Sistema de Contas Nacionais, seguindo as recomendações internacionais compiladas no System of National Accounts de 1993, com dados desde 1990.
} 